\title{
Mechanical Properties and Microstructure of Friction Stir Spot Welded 6082-T6 Aluminium Alloy Joint
}

\author{
Nurul Muhayat ${ }^{1, *}$, Bobby Priatmana Putra ${ }^{1}$, and Triyono ${ }^{1}$ \\ ${ }^{1}$ Mechanical Engineering Department -Sebelas Maret University, Indonesia
}

\begin{abstract}
Friction stir spot welding (FSSW) can substitute resistance spot welding (RSW) to avoid the problem due to melting materials during welding. In this investigation, a friction stir spot welded $6082 \mathrm{~T} 6$ joint was made to study the effect of pin diameter and dwell time on mechanical properties and microstructure with variation of pin diameter and dwell time. In the stir zone, it is observed that the grain structure is fine equiaxed recrystallized grain whereas in the HAZ, it is coarse grain. The increase of pin diameter and dwell time lead to the increase of tensile shear load. The highest tensile-shear load obtained is $4987.1 \mathrm{~N}$ at the highest pin diameter of $7 \mathrm{~mm}$ and dwell time of 3 seconds, while the lowest one is $788.2 \mathrm{~N}$ that obtained at pin diameter pin of $3 \mathrm{~mm}$ and dwell time 3 second. The highest micro Vickers hardness obtained at stir zone of $96.2 \mathrm{VHN}$, while the lowest one is $42.1 \mathrm{VHN}$.
\end{abstract}

\section{Introduction}

Maximizing fuel consumption efficiency and minimizing gas emissions can be achieved by reducing vehicle weight. Although the strength of aluminium is relatively lower than steel but the density of aluminium is one third compared to steel [1] so that the use of aluminium alloy can reduce the total weight of the vehicle. Aluminium alloy can be used in low load structures while steel can be used in high load structures.

Various methods have been used in automotive industry for joining steel such as resistance spot welding (RSW) and riveting. Recently friction stir spot welding (FSSW) that is a new developed of FSW can be used to replace the RSW process in joining aluminium alloy. RSW process has many disadvantages in welding aluminium such as porosity distortion and residual stress [2]. The FSSW process is started by plunging a rotating tool into an upper plate until the surface of bottom plate with a certain depth. The rotating tool blend both the upper and bottom plate materials beneath shoulder for a while and finally the rotating tool is withdrawn. There is an existing hole that similar to dimension of the pin tool [3].

The FSSW process give rise to welding heat by the friction of the tool and the surface of the work piece when the material is processed. The tool is composed of shoulder and pin. The role of the tool is to elevate temperature of base materials and to stir the materials around the tool during the process and causing unify between upper and lower plate [4].

FSSW process transpire in solid state that result in some advantages due to low heat generation such as low distortion, good mechanical properties and absence melted related defect. It can be a potential surrogate for RSW process on joining aluminium and steel plates [5]. This process fabricate weld joint with no melting and solidification cycle, low energy, small residual stress, environmentally friendly and low cost [6]. The low friction heat of welding process is expected to enhance the aluminium 6082 T6 welded joint that caused by excessive heat input of welding process in fusion welding process such as RSW. The aims of this research is to investigate the effect of dwell time and pin diameter in friction stir welded AA6082-T6 joints.

\section{Experimental procedure}

A commercial $6082 \mathrm{~T} 6$ aluminium alloy were used as a base material for FSSW process. The size of the tensile shear specimen was $100 \times 25 \times 3 \mathrm{~mm}$ with overlap area $50 \times 50 \mathrm{~mm}$ to be welded with configuration of lap joint as seen in Figure 1.

The rotational speed of $1600 \mathrm{rpm}$, shoulder diameter of $12 \mathrm{~mm}$ and shoulder plunge depth of $1 \mathrm{~mm}$ were selected as fixed welding parameters.

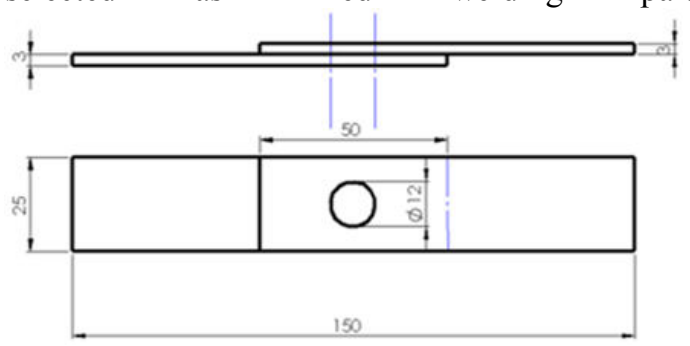

Fig. 1. Configuration of FSSW specimen 


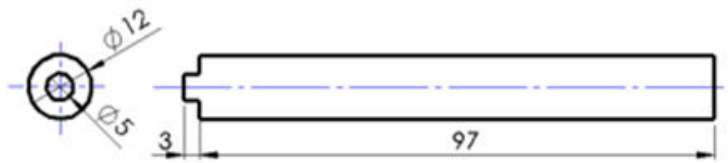

Fig. 2. Schematic diagram of FSSW tool

Three different pin diameter of 3,5,7 $\mathrm{mm}$ and four different dwell time variation of $3,5,7,9$ second were chosen to fabricate the specimen. Figure 2 shows the dimension of the tool. All the friction stir spot welded specimen was subjected mechanical and physical test to study the effect of welding parameter on mechanical and physical properties of the $6082 \mathrm{~T} 6$ lap joint.

The specimen of metallographic examination were cut across the joint and then polished using multi grade of emery paper and etched with modified Poulton's reagent $(30 \mathrm{~mL} \mathrm{HCl}, 40 \mathrm{~mL} \mathrm{HNO}, 2.5 \mathrm{~mL} \mathrm{HF}, 12 \mathrm{~g}$ $\mathrm{CrO} 3$ and $42.5 \mathrm{~mL} \mathrm{H} 2 \mathrm{O}$ ). The microstructure images were taken by an Optical Euromex Holland Microscope whereas the macrostructure images were observed by a light optical stereo zoom microscope.

The micro Vickers hardness measurement was undertaken using Vickers Highwood HW MMT X7 with load of $0.2 \mathrm{kgf}$ for 10 seconds. Tensile shear load test was carried out by using a universal testing machine. This test was taken to establish the tensile shear load of the weld joint.

\section{Result and Discussion}

\subsection{Microstructure}

A 6082 T6 aluminium alloy is heat treatable alloy that mechanical properties is influenced by the changes of precipitate feature. Macroscopic observation shows the cross section of the 6082 T6 FSSW joints that displays micro structurally different zone as shown in Figure 3. There are base material (BM), heat affected zone (HAZ), thermo mechanically affected zone (TMAZ) and stir zone (SZ).

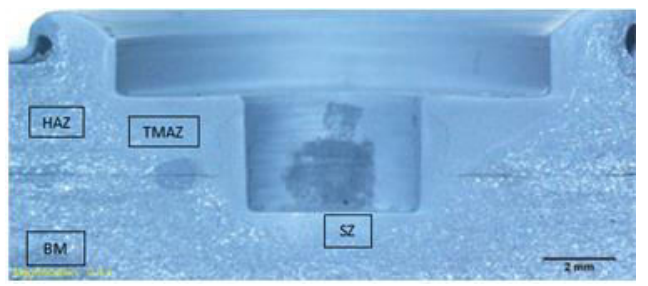

Fig. 3. The cross section of FSSW specimen

Figure 4 exhibits the microstructure of HAZ under variation of dwell time and pin profile. The HAZ grain size are coarser than that of base materials. The increase of dwell time and pin diameter lead to the increase of grain size. It can be explain that the increase of dwell time and also pin diameter cause the higher heat input that exposed to the vicinity of the joint. The grain size will grow due to the excessive heat input [4].

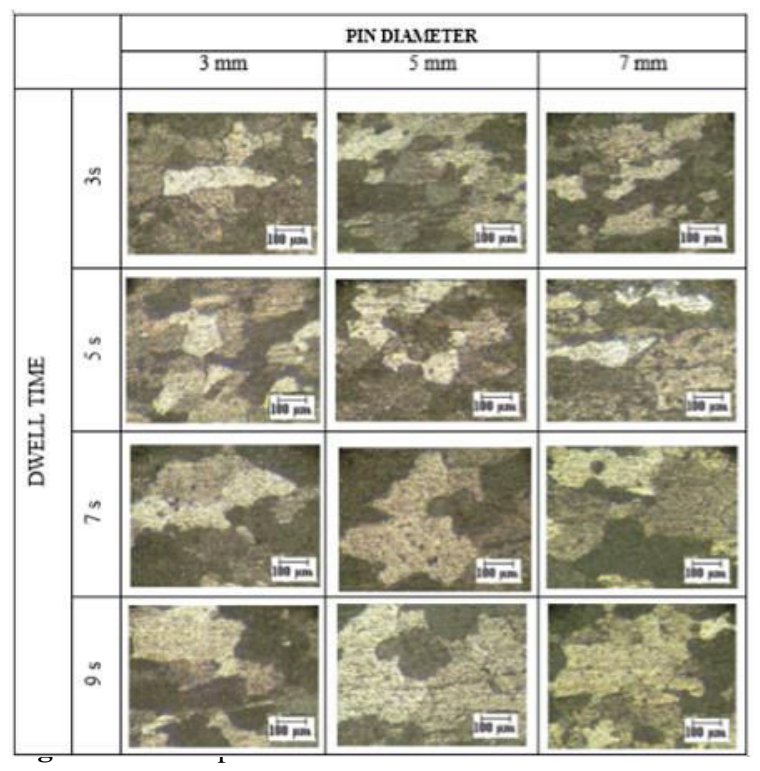

Fig. 5. Microscopic observations of the HAZ region

Fine precipitates of $\mathrm{Mg} 2 \mathrm{Si}$ spread evenly in the mixture of aluminium matrix dispersion throughout the area. The specimen that produced with pin diameter of 3 and $5 \mathrm{~mm}$ for all variation of dwell time show the increase of $\mathrm{Mg} 2 \mathrm{Si}$ precipitate within grain. On the other hand the specimen that fabricated with pin diameter of 7 $\mathrm{mm}$ for all variation of dwell time indicate the changes of the size Mg2Si phase to be coarser precipitate [7].

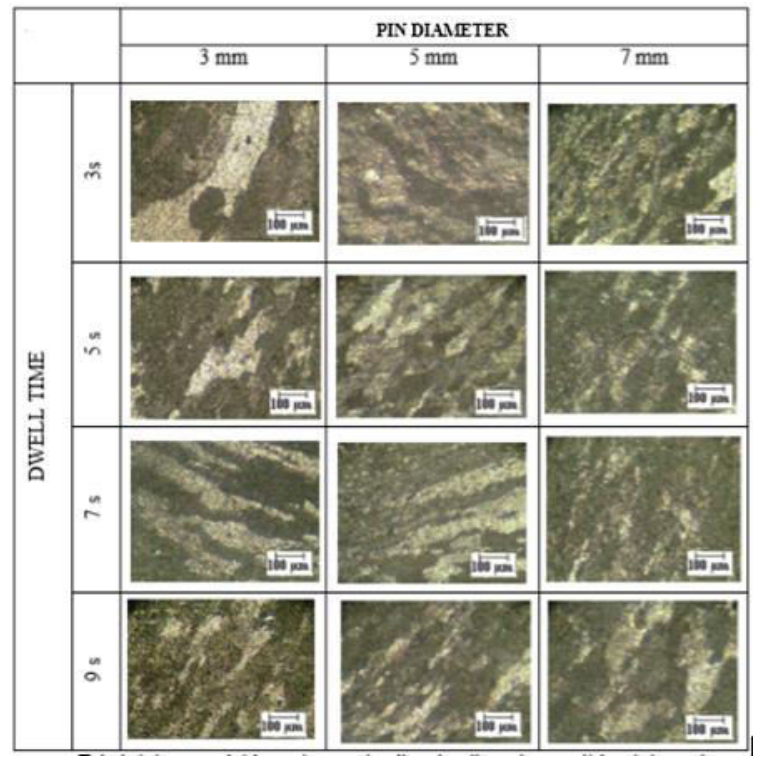

Fig. 5. Microscopic observations of the TMAZ region

The HAZ region experience the increase of temperature, it decrease the strength of the HAZ region by coarsening and dissolution of particle precipitation [8].

Figure 5 indicates typical microstructure of TMAZ under variations of dwell time and pin diameter. It can be identified that the type grain of TMAZ is smaller elongated grains compared to typical grain of HAZ region. This zone is an area influenced by thermal cycles 
and severe plastic deformation due to contact action between the tool and the material during welding process. It is denoted from the orientation and size of the grain.

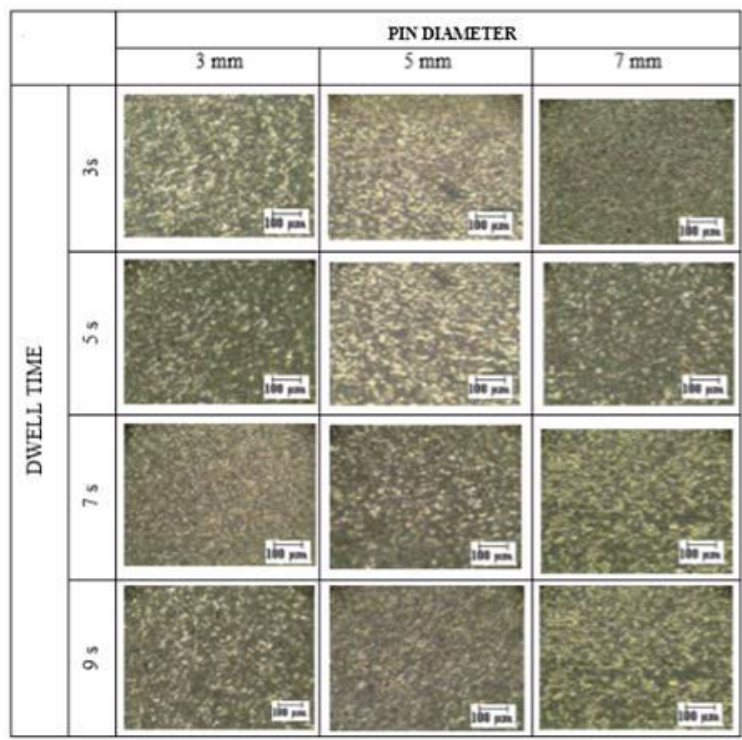

Fig. 6. Microscopic observations of the SZ region

The microstructure of stir zone can be seen at Figure 6 . The stir zone is characterized by fine equiaxed grains structure compered to the HAZ and TMAZ region result of dynamics recrystallization. When the increase of dwell time and pin diameter, the stir zone exhibit the higher grain size. It is well known that the increase of dwell time and pin diameter will increase heat input that result in coarser re-crystallized grain size. The recrystalized grain size be contingent on the degree of plastics deformation and heat input of welding process [7].

\subsection{Hardness}

The points of Vickers micro-hardness test with the interval of $1 \mathrm{~mm}$ can be found at Figure 7. The result of Vickers micro-hardness under variation of pin diameter of 3,5,7 mm for all variation dwell time are plotted at Figure 8, 9 and 10 respectively. Generally the lowest hardness number can be obtained at the 2nd point from surface of pin as shown an arrow at Figure 7. It means that the lowest hardness lay on the region HAZ adjacent to the TMAZ. The lowest hardness of $42.1 \mathrm{HVN}$ in the HAZ region is obtained at the specimen with pin diameter of $7 \mathrm{~mm}$ and dwell time of 9 second. This region undergo two softening mechanism. The first is softening by coarsening grain and the second is dissolution of precipitate. According to [9] the rise of temperature cause the decrease needle shape precipitate whereas the rod shape ones increase.

The changes of microstructural can lead reduction of hardness number. On the other hand the HAZ region far from TMAZ expose to temperature relatively low than that of the region adjacent to the TMAZ.

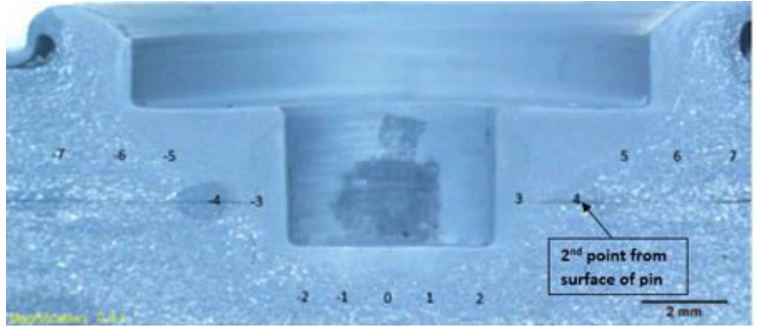

Fig. 7. The point of micro Vickers hardness testing

It result in the higher hardness due to the coarsening grain softening mechanism. The hardness of TMAZ region is higher than that of HAZ due to the higher degree of deformation that indicated by elongated grain.

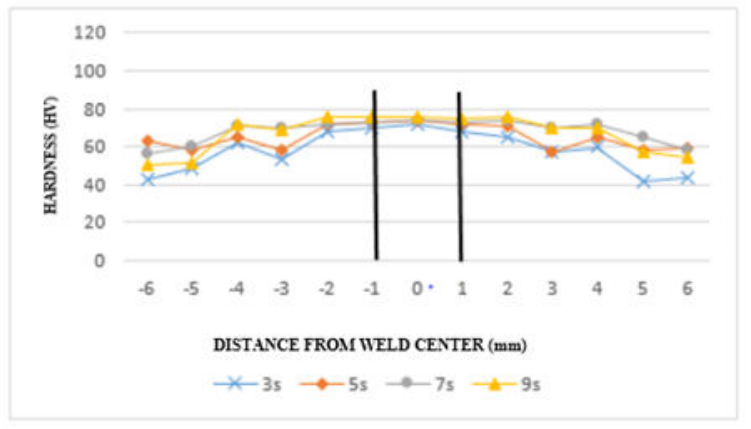

Fig. 8. Micro Vickers Hardness under pin diameter of $3 \mathrm{~mm}$ and variation of dwell time

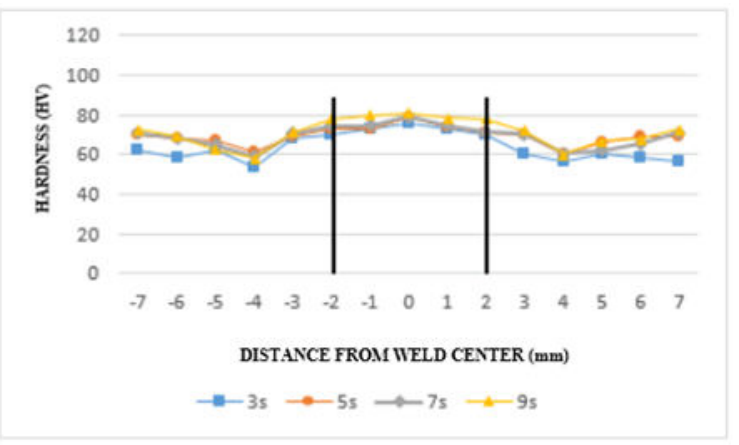

Fig. 9. Micro Vickers Hardness under pin diameter of $5 \mathrm{~mm}$ and variation of dwell time

The highest hardness of $96.2 \mathrm{HVN}$ is found at SZ region beneath the pin of specimen that fabricated with the dwell time of 3 second and pin diameter of $7 \mathrm{~mm}$ whereas for the lowest ones of 64.7 is found at the one with dwell time of 3 second and pin diameter of $3 \mathrm{~mm}$. The SZ region underwent the highest temperature that can dissolved all the needle precipitate result in supersaturated solid solution [9]. The highest hardness number in this region is attributed to the fine grain due to dynamic re-crystallization [10] and the changes of microstructure [11]. 


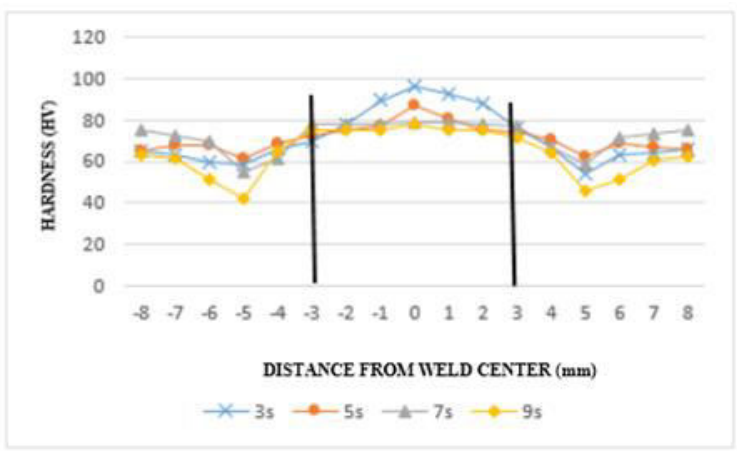

Fig. 10. Micro Vickers Hardness under pin diameter of $7 \mathrm{~mm}$ and variation of dwell time

\subsection{Tensile shear load}

Figure 11 displays tensile shear load of FSSW 6082 T6 specimen under variation of dwell time and pin diameter. As shown in Figure 11, at constant dwell time, the tensile shear load rise when the pin diameter increase. The tensile shear load reaches the its maximum of $4987.1 \mathrm{~N}$ when the pin diameter of $3 \mathrm{~mm}$ and dwell time of 7 second. The lowest tensile shear is $788.2 \mathrm{~N}$ when the pin diameter of $3 \mathrm{~mm}$ and dwell time 3 second.

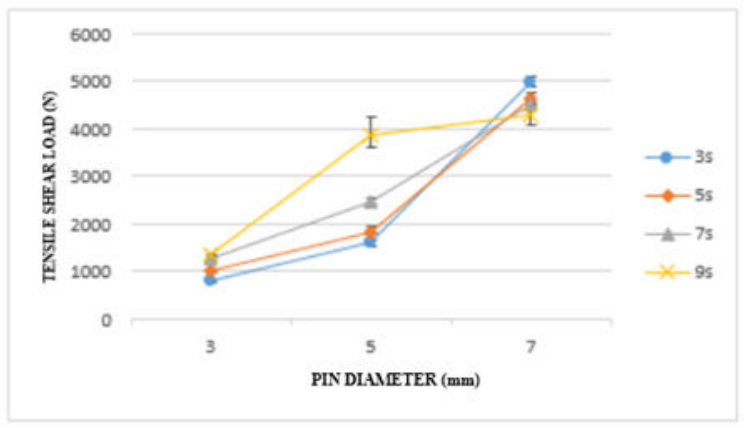

Fig. 11. Tensile shear Load under variation of dwell time and pin diameter

The highest dwell time 7 second means that highest heat input among dwell time variation. Consequently, the soften material that can be stirred become wider. It influences the bonding area between two plate that lead to rise the tensile shear load.

In line with the increase of dwell time, the increasing diameter size, also makes the mixing process of the material around the pin to be better due to the adequate heat input result of friction contact by the greater the pin diameter [12]. The boundary between upper and lower material is completely destroyed [13]. It can make the better unify between upper and lower plate. Metallurgical bonding area has a significant role on the tensile shear load of specimen [4].

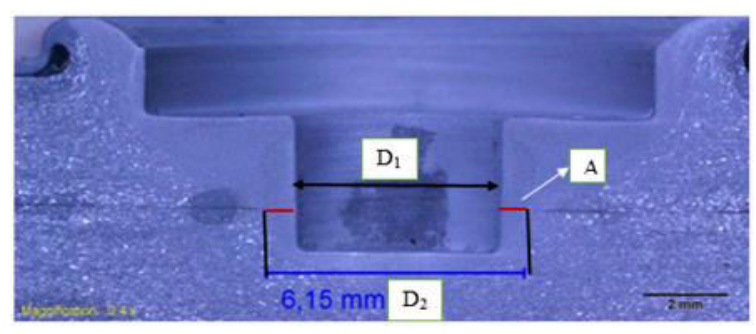

Fig. 12. Metallurgical bonding area at FSSW joint

Figure 12 shows the metallurgical bonding area of FSSW joint indicated by red line. This circle area can be given from the formula $\mathrm{A}=\pi(\mathrm{D} 12-\mathrm{D} 22) / 4$. The size bonding area under variation of dwell time and pin diameter can be plotted in Figure 13.

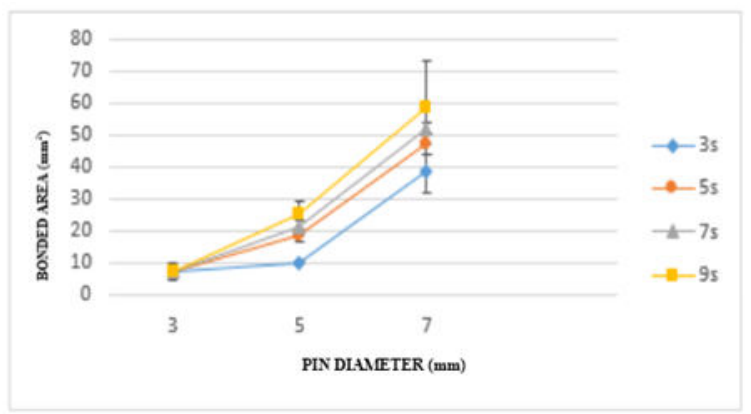

Fig. 13. Calculated metallurgical Bonding area

According to Figures 11 and 13, it can be concluded that the rise of pin diameter for all variation dwell time enlarge the metallurgical bonded zone. Tensile shear load of the welded joint is proportional to the effective bonding area for the increase of pin diameter of 3 to 5 $\mathrm{mm}$ for all variation of dwell time.

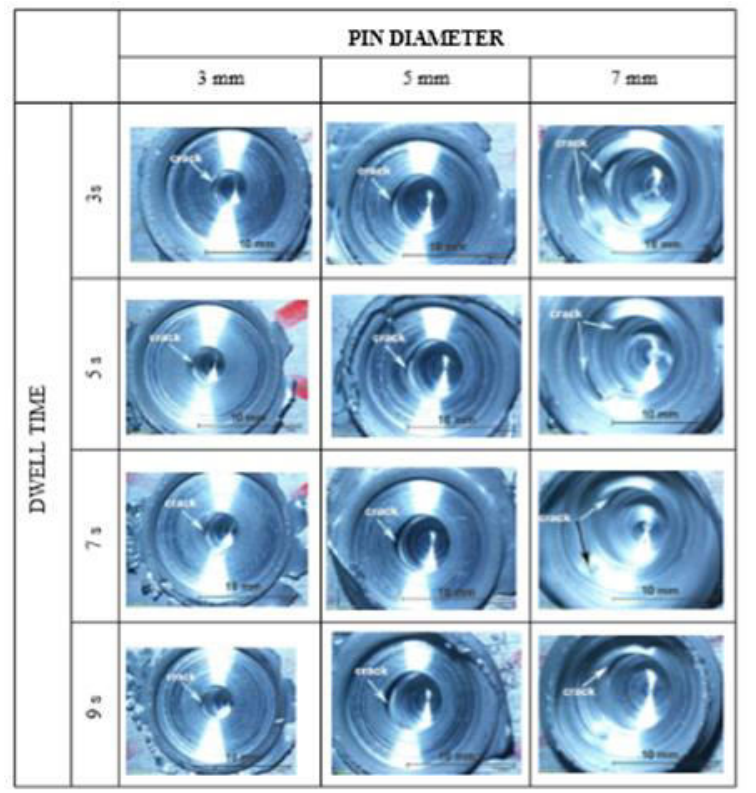

Fig. 14. Fracture mode of FFSW joint under variation of dwell time and pin diameter 
With further increase of pin diameter from $5 \mathrm{~mm}$ to 7 $\mathrm{mm}$ for all variation of dwell time, tensile shear load of the joint become inappropriate with the trend of the bonded area. The lowest bonded area, get the highest tensile shear load whereas the widest bonded area get the lowest one.

The specimen that produced with welding parameter of the highest dwell time of 9 second and the highest pin diameter $7 \mathrm{~mm}$ get the widest bonded zone but it gets the lower than that of the highest dwell time 7 second and pin diameter $3 \mathrm{~mm}$. It can be explained that the specimen with the highest dwell time of 9 second and highest pin diameter of $7 \mathrm{~mm}$ generated excessive heat input. The excessive heat input lead to the grain growth and coarsening precipitate that can decrease the tensile shear load.

Figure 14 exhibits the fracture mode of specimen of FSSW under variation of pin diameter and dwell time. The result of this observation is found that the type of fracture of this tensile shear test is pull out type that is combination between shear fracture and tensile fracture. Pull out mode failure shows high tensile shear load and also high fracture energy due to the high metallurgical bonded zone [8].

\section{Conclusion}

Mechanical properties and microstructure of friction stir spot welded $6061 \mathrm{~T} 6$ aluminium alloy joints have been investigated based on welding parameter of pin diameter and dwell time. The following conclusion can be drawn:

1. The increase of dwell time and pin diameter lead to the increase metallurgical bonded zone, grain size and the appearance of the $\mathrm{Mg}_{2} \mathrm{Si}$ phase size become coarser precipitate.

2. The increase of dwell time and pin diameter lead to the increase of tensile shear load of friction stir spot welded 6082 T6 joint. The excessive heat input, such as pin diameter of $7 \mathrm{~mm}$ and dwell time $9 \mathrm{~s}$ caused slightly drop of tensile shear load.

3. The increase of dwell time and pin diameter lead to reduction of micro Vickers hardness number.

\section{References}

1. J.W. Kwon, M. S. Kang, S. O. Yoon, Y. J. Kwon, S. T. Hong, D. I. Kim, K. H. Lee, J. D. Seo, J. S. Moon, K. S. Ha, Trans. Nonferrous Met. Soc. China 22, s624-s628 (2012).

2. A.M.S. Malafaia, M.T. Milan, M.F. Oliveira, D. Spinelli, Procedia Eng, 2(18): pp. 7. (2010)

3. W. Yuan, R.S. Mishra, S. Webb, Y.L. Chen, B. Carlson, D.R. Herling, G.J. Grant,. J. Mater. Process. Technol, 211: pp. 6. (2011)

4. N. Muhayat, Triyono, R.D. Rachmanto, A. Zubaydi, J. Mech. Eng. Vol SI 5(1), 181-191, (2018)

5. Y. Uematsu, and K. Tokaji, Sci Technol Weld Joining, (2009). 14: pp. 10.
6. R.S. Coelho, A. Kostka, J.F. dos Santos, A. KaysserPyzalla, Mater. Sci. Eng. A. (2012). 556: pp. 175183.

7. D.M. Rodrigues, A. Loureiro, C. Leitao, R.M. Leal, B.M. Chaparro, P Vilaca, Mater Des, (2009). 30(19): pp. 9.

8. M. Reinman, T. Gartner, U. Suhuddin, J. Göbel, J.F. dos Santos, J. Mater. Process Technol. 237 (2016) $12-18$

9. M. Fujimoto, S. Koga, N. Abe, Y.S. Sato, and H. Kokawa, Sci. Technol. Weld. Joining (2008) VOL 13 NO 7

10. R.S. Mishra, and M. Mahoney, Friction Stir Welding and Processing. ASM International, 2007.

11. H. Badanirayan, Q. Yang, and S. Zhu, Int J Mach Tools Manuf 2009. 49: pp. 8.

12. J. Shen, D. Wang, and K. Liu, Sci. Technol. Weld. Joining, 2012. 17: pp. 8.

13. H. Liu, Y. Zhao, X. Su, L. Yu, L. Hou, Adv. Mater. Sci and Eng., 2013: pp. 10 